\title{
Chapter 15 \\ Ageism in Mental Health Assessment and Treatment of Older Adults
}

\author{
Ehud Bodner, Yuval Palgi, and Mary F. Wyman
}

\subsection{Ageism Among Mental Health Clinicians and Patients}

\subsubsection{Ageist Attitudes and Perceptions Among Mental Health Clinicians}

As mental health clinicians, we strive to meet, treat, and be with our patients through their own experiences, tribulations, and personal journeys. However, when a psychotherapist (for example, a social worker, a psychologist, or a psychiatrist) encounters an older patient, he or she may be subject to ageist judgements which stem from a stereotypical view of older adults in general, regardless of how the individual patient presents him or herself. Perhaps the seed of these ageist attitudes among psychotherapists can be located in Freud's view (1905/1953) on the lack of mental flexibility of older adults, which, he argued, impedes their ability to benefit from psychotherapy. Seventy years later, this scepticism among psychotherapists toward the value of both psychotherapy and medical treatment for the aged was characterized by Butler (1975) as "therapeutic nihilism." According to Butler, such an

\footnotetext{
E. Bodner $(\bowtie)$

Interdisciplinary Department of Social Sciences and Department of Music, Bar Ilan University, Ramat Gan, Israel

e-mail: ehud.bodner@biu.ac.il

Y. Palgi

University of Haifa, Haifa, Israel

e-mail: ypalgi@research.haifa.ac.il

M. F. Wyman

W. S. Middleton Memorial Veterans Hospital and University of Wisconsin School of Medicine \& Public Health, Madison, WI, USA

University of Freiburg, Freiburg im Breisgau, Germany

e-mail: mfwyman@wisc.edu

L. Ayalon, C. Tesch-Römer (eds.), Contemporary Perspectives on Ageism, International Perspectives on Aging 19, https://doi.org/10.1007/978-3-319-73820-8_15
} 
attitude represents a self-fulfilling prophecy, generated by ageist behaviors, which prevents clinicians from examining the validity of their views about the aged.

Ageism in the form of age discrimination and age stereotypes is considered a domain-specific phenomenon (see Voss et al.'s Chap. 2). A lot has been written in general about ageism in the domains of health care systems and long term care (see the chapters in this volume by Wyman et al. Chap. 13 and Buttigieg et al. Chap. 29). However, less has been published about ageism in the domain of mental health. Nevertheless, a number of studies over the last three decades have demonstrated the existence of negative attitudes toward older adults among psychotherapists. For example, Dye (1978) found negative views regarding the ageing process, and a preference against working with older patients, in a large sample of clinical and counseling psychologists in the USA. Older persons were described by the psychologists as being rigid, as having difficulties in learning new material, and as lacking the required energy and resilience for therapeutic growth. Two other studies eliciting assessments of standardized case vignettes from 179 psychiatrists (Ford and Sbordone 1980), and from 407 licensed clinical psychologists in the U.S.A (Ray et al. 1987) found that older patients consistently received less favorable prognoses than their younger counterparts and were perceived as less ideal for therapy. Moreover, in Israel, 55\% of a sample of clinical psychologists indicated their reluctance to work with older patients (Shmotkin et al. 1992), and in Great Britain, psychiatrists were less likely to recommend psychotherapy for sexual dysfunction to an older patient compared with a younger patient (Bouman and Arcelus 2001; see Gewirtz-Meydan and colleagues in this volume).

In Australia, Helmes and Gee (2003) presented 414 psychologists and 293 counselors with a vignette describing a fictitious case, and found that an older patient was rated as less able to create proper therapeutic relationship, as having a poorer prognosis, and as being less appropriate for therapy compared with a younger patient with the same symptoms. More recently, a review demonstrated an age bias among psychotherapists, with many expressing the view that depression in late life is a natural consequence of old age and that old age is a phase of life associated with less satisfaction and diminished personal growth (Laidlaw and Pachana 2009). In Portugal, Gonçalves and colleagues (Gonçalves et al. 2011) found that compared with nursing and social work undergraduates, psychology students expressed the most negative attitudes, the lowest level of knowledge, and the lowest level of interest in working with older adults.

An urgent issue which emphasizes the existence of negative attitudes toward older adults among psychotherapists concerns the legitimacy of suicide in older adults. Uncapher and Arean (2000) found that USA physicians were less interested in treating older adults with suicidal tendencies than they were in treating younger patients with identical problems. According to the physicians' view, the existence of suicidal tendencies among older adults was seen as logical and normal. Hence they were less willing to use therapeutic strategies to address suicidal thinking in older patients. In another study (Barnow et al. 2004), German medical professionals (physicians and nurses working in psychiatric institutions), in response to a vignette describing an older client, were less likely to suggest treatment to patients exhibiting 
suicidal tendencies compared to an identical vignette featuring a young client. Here, too, health professionals working in psychiatric institutions expressed less willingness to treat older compared to younger suicidal patients.

These biases against older patients appear to be formed well before mental health clinicians enter the professional world. A survey of clinical psychology trainees (Lee et al. 2003) revealed predominant perceptions of older adults as being people who are resistant to new things, have limited opportunities, demonstrate rigidness and inflexibility, and have a very limited potential to change, as they are too close to the end of their lives. Many of the trainees believed that psychotherapy was problematic in this age group due to cognitive problems, such as difficulties with memory $(74.4 \%)$, concentration $(61.2 \%)$, and mental rigidity $(60.4 \%)$. The psychotherapists also identified other challenges to working with older patients, such as a decline in hearing (60.4\%), apathy $(57.1 \%)$, passivity (46.6\%), difficulties in learning new material (45.3\%), problems in changing habits (44.5\%), and a lack of psychological mindedness (56.9\%).

To sum up, evidence from across the globe over the last 30 years demonstrates that many mental health clinicians are less willing to work with older adults, have negative assumptions about the effectiveness of psychotherapy with older adults, and lack professional knowledge of the geriatric population.

\subsubsection{Training in Geriatric Mental Health and Exposure to Older Patients}

Curriculum content in mental health training programs has traditionally been lacking in material related to geriatric patients and in clinical skills for working with the older population (e.g., Qualls et al. 2002). Subsequent professional work experiences often do not allow for adequate exposure to older patients. For example, data on the current major fields of APA members in 2015 show that only 240 health services providers out of 43,353 , reported Geropsychology as their main area (APA Center for Workforce Studies 2015 reported in American Psychological Association 2015). A survey in Australia also found that only $6 \%$ indicated they were specialists in aged care, and $40 \%$ of the sample reported having no contact at all with older patients (Koder and Helmes 2008). In the UK, similar figures were reported (Bryant and Koder 2015).

As a result, many mental health professionals report a lack of specific knowledge about psychopathology and psychotherapy with older adults. For example, in Britain, trainees in psychotherapy expressed a lack of information about psychotherapy with older adults (Scott and Bhutani 1999), and recruiting psychologists to work with older adults has been challenging (e.g., Britton and Woods 1996). American psychologists reported minimal formal education in geropsychology and endorsed the need for additional training (Qualls et al. 2002). A survey among 200 clinical psychologists in training programs found that many reported having "less to 
offer" to older patients compared to patients from other age groups (Lee et al. 2003). Another study in Britain (Richards et al. 2007) conducted 30 interviews with health and social care practitioners currently working with older people. This study found that the practitioners lacked essential theoretical and research-based knowledge in the field of ageing and old age; rather, they primarily made use of common organizational policies and personal experience with ageing family members to analyze a clinical vignette presented to them.

In summary, the lack of knowledge and training in geriatric care, especially in the field of clinical psychology, presents a global problem, in particular in the context of demographic trends toward an increase in the aged population. Lack of specialized geriatric knowledge was found to be an influential factor in the negative attitudes of psychologists toward older adults (Koder and Helmes 2008). This problem begins at the undergraduate psychology education level, as most courses do not include content on the psychology of old age, and continues through the advanced training of clinical psychologists specializing in geriatric care (Bryant and Koder 2015; Qualls et al. 2002). This lack of knowledge in geriatric mental health and the minimal exposure to older patients among mental health clinicians may be the main reason for their reluctance to work with older adults and a primary contributing factor to stereotyped "ageist" attitudes. Therefore, clinical exposure to the aged has frequently been suggested as a means to mitigate pre-existing negative stereotypes concerning older adults (Bryant and Koder 2015; Koder and Helmes 2008).

Nevertheless, the factors underlying age-based bias in mental health care are numerous. Research suggests that an additional reason for these attitudes among clinicians may be the way elderly patients internalize ageist social stereotypes, and how the patients themselves perceive their psychiatric problems (Laidlaw and Pachana 2009). In the next subsection we will change our perspective from the psychotherapist to the patient, discuss self-ageism among older mental health patients, and elaborate on the effect of self-ageism on the encounter between older mental health patients and clinicians.

\subsubsection{Self-Ageism Among Older Patients with Mental Illness}

One out of five persons above the age of 65 suffers from some form of mental illness (e.g., Karel et al. 2012). The majority of these older adults prefers to consult a primary general practitioner and does not seek out mental health clinicians (Lerner and Levinson 2012). Unfortunately, primary general practitioners encounter barriers to the management of mental illness both at the individual and the system levels (Ayalon et al. 2016). But more importantly, when referrals to mental health practitioners are made, older adults are unlikely to follow through on these referrals, and thus further assessment often does not occur (DiNapoli et al. 2015). Therefore, it is essential to examine the reasons for older adults' reluctance to use mental health services. 
When older adults relate to a social group which may be discriminated against, based on their skin color, race, gender, or being a cultural minority (see Krekula et al.'s Chap. 3 on gendered ageism, and also Dolberg et al.'s Chap. 12 on ageism and older immigrants), they may experience double- jeopardy and stigmatization. This may also be the experience of older adults who suffer from mental health problems. One unique problem that older adults with mental illness face is "double stigmatization," which refers to negative attitudes toward old age combined with negative attitudes toward mental illness (Werner et al. 2009). "Self-double stigmatization" is the internalization of these stigmas by those who are the target of double stigmatization (Rush et al. 2005). Self-double stigmatization may have a negative effect on the ability of older adults with psychiatric conditions to seek help from mental health professionals. Studies have shown that internalized stigma related to mental illness (e.g., schizophrenia) makes it more challenging for the patient to seek therapy (Fung et al. 2007) and to comply with recommendations in psychotherapy (Mackin and Arean 2007).

Several researchers have examined double stigmatization associated with depression in old age. Depression is one of the most prevalent mental illnesses in the population of older adults, with a prevalence estimates in the general elderly population ranging from $1-4 \%$ for major depression, $4-13 \%$ for minor depression (Blazer 2003), and $8-16 \%$ for significant depressive symptoms (Blazer 1989). Depression is a stigmatized illness and may be seen as a sign of personality weakness and as something to hide. Therefore, there are societal negative attitudes toward depressive patients (e.g., Boardman et al. 2011). It has been suggested that negative attitudes towards depressive patients harm self-esteem and can worsen symptoms (Fung et al. 2007).

In addition, negative self-perceptions of ageing are associated with increased depressive symptoms in later life (e.g., Wurm and Benyamini 2014). Two crosssectional studies have pointed to the link between more positive attitudes toward ageing and less depression (Bryant et al. 2012), which has also been found in relation to subsyndromal depressive symptoms (Chachamovich et al. 2008). Moreover, a recent study of over 2000 older military veterans in the U.S. has found that those who had more negative stereotypical perceptions of their own ageing, reported a higher frequency of psychiatric symptoms, in comparison with those who had fewer negative stereotypical perceptions of ageing (Levy et al. 2014). Group differences were found in rates of suicidal ideation (30.1\% vs. $5.0 \%)$, anxiety symptoms (34.9\% vs. 3.6\%) and Post Traumatic Stress Disorder (PTSD) symptoms (18.5\% vs. $2.0 \%$ ), and were maintained after relevant sociodemographic variables were controlled for.

Whereas higher negative self-perceptions of ageing are associated with more severe psychopathology, double stigmatization further impedes the tendency of older mental health patients to seek help from mental health professionals (e.g., Fung et al. 2007). Several researchers have suggested that the underutilization of mental health services by older adults may result from the internalization of ageist attitudes by older patients (Levy 2003). Consequently, the difficulties that older patients experience in mental health treatment likely increase as their mental condition persists or even worsens as a result of their inability to receive help. 
When trying to understand the mechanisms responsible for the association between negative self-perceptions of ageing and proneness to severe psychopathology, ageism can be identified as a stressor in its own right. According to Ingram and Luxton's (2005) stress and vulnerability model, exposure to various environmental stressors is linked with an increased risk for developing psychiatric conditions. Following this line of thought, people who hold negative attitudes toward their ageing may be less willing to take part in positive social activities (Weiss and Lang 2012), and may hold negative images of age-related health problems. This may in turn result in an increased vulnerability to depression, that is, a type of "selffulfilling prophecy" (Kessler and Bowen 2015). In contrast, positive attitudes toward ageing may act as a buffer against mental distress, as older adults with more positive attitudes toward ageing seem to become more involved in healthier ways of living, such as maintaining a nutritious diet (Huy et al. 2010) or engaging in regular physical activity (Levy and Myers 2004).

There is also empirical evidence indicating that ageism is associated with heightened ageing anxiety (Bodner et al. 2015a). These concerns act as stressors that increase sensitivity to physical symptoms (Poon and Knight 2009), and become associated with higher levels of depression during midlife (Barrett and Robbins 2008), as well as with other symptoms of mental distress (Bodner et al. 2015b). Of note, these findings are also consistent with the behavioral model of late life depression (Fiske et al. 2009), which regards negative cognitions about the self and the future as risk factors for depression in late life.

In summary, older adults with mental health problems may hold both ageist negative attitudes toward themselves as well as negative attitudes toward mental illness. This self-double stigmatization may have an impact on their symptoms and their interactions with the mental health care system. Following this line of thought, in the next subsection we will discuss the objective difficulties clinicians face when diagnosing mental health problems in older adults. Then, we will examine how ageist attitudes of both clinicians and patients may impact the accuracy of several mental health diagnoses and subsequent treatment recommendations.

\subsection{Difficulties in the Assessment of Older Persons with Mental Health Problems: The Impact of Ageism}

\subsubsection{Objective Difficulties in Assessing Psychiatric Conditions in Old Age}

For a number of reasons, the assessment of mental health disorders in older adults can be complex and often requires a high level of expertise, effort, and time. In old age, there is an overlap between some psychiatric symptoms and symptoms related to changes in hormone levels (Sternbach 1998), declines in cognition (Petersen 2004), physical disability (Milaneschi and Penninx 2014), and physiological 
processes (McKinney and Sibille 2013). These non-psychiatric symptoms are often part of normal ageing. For example, needing less sleep, changes in diet and digestive functioning (Elsner 2002), reduction in energy, and slowed information processing are considered normal age-related changes (Whitbourne and Krauss 2011). However, these symptoms can also be part of the clinical presentation associated with common disorders such as anxiety or depression (Fiske et al. 2009). Teasing apart the etiology or multiple etiologies of such symptoms can be very challenging when working with an older patient.

Another challenge to accurate diagnosis of mental health problems in older adults lies in the limitations of available psychiatric assessment tools. Mental health symptom questionnaires and interview instruments have been criticized for inadequately discerning between age-related problems and psychiatric symptoms (Eisner et al. 1999) and may not have been validated with older adult samples (Owens et al. 2000). Despite the fact that many scholars have studied this issue and considered potential solutions (e.g., Hendrie et al. 1995), there is, as of yet, no clear consensus on an optimal approach to the assessment of mental health conditions in older adults. Moreover, as noted above, many mental health clinicians have not received adequate basic education in geriatric mental health and thus may experience additional challenges in providing assessment and treatment for complicated older adult cases (Halpain et al. 1999). If we add to this the fact that older adults prefer primary general practitioners, and refrain from seeking out mental health clinicians (Lerner and Levinson 2012), we end up with another almost impossible challenge for the practitioner - to make a psychiatric diagnosis and treat other medical age-related conditions in the brief time allotted to that patient.

A further issue concerns the clinical presentation of mental disorders. Clinicians and researchers have long reported age differences in symptom constellation of some mental disorders, such as depression (see Blazer and Hybels 2005) and PTSD (Palgi 2015; Pietrzak et al. 2012). However, age-based comparisons of symptom presentations have found mixed results (e.g., see Luppa et al. 2012 for evidence suggesting an increase in depression with aging, and a review by Debast et al. 2014, reporting age differences in somatoform disorders). The mixed results in the literature have not helped to decrease clinician bias and confusion in this domain. Adding to this is the mounting evidence that subthreshold mental disorders are more prevalent than diagnosed disorders in late life and are associated with significant disability and comorbidity (e.g., Meeks et al. 2011). Together, these factors make the diagnosis of mental disorders in old age more difficult.

Eliciting older patients' own attributions for their problems, whether physical or emotional, is an important piece of the diagnostic process for the clinician. However, when the etiology of the symptoms is unclear, such attributions may further complicate the clinical picture. Research suggests that older adults with depression may tend to blame themselves and their lifestyle choices for their own medical symptoms, while making different attributions for the same symptoms in others (Benedict 1995). They may attribute physical symptoms (for example, fatigue, concentration problems, and weight loss) to medical diagnoses and not to psychiatric conditions, which may affect responses on self-report mental health measures and in 
interview-based assessments. In addition, older adults may not endorse the "impairment in social or occupational functioning" needed to meet DSM diagnostic criteria for mental disorders. It can be difficult for both patient and clinician to identify impaired functioning when a retired or disabled older adult has few social roles or formal responsibilities (Hendrie et al. 1995). Further, willingness on the part of older adults to admit impairment may be related to ethnicity or cultural values (e.g. Apesoa-Varano et al. 2015).

To sum, the interaction between age-related changes and the clinical phenomenology of psychiatric problems in old age makes it more challenging and timeconsuming for patients and clinicians to accurately perceive and diagnose psychiatric conditions. It can be especially problematic when these objective difficulties in diagnosing psychiatric syndromes in late life are combined with stereotypes based on age, in both patients and clinicians.

\subsubsection{Psychiatric Diagnoses Biases in Late Life: The Role of Ageism}

In this subsection we discuss four specific psychiatric syndromes which can be difficult to diagnose in old age. We raise concerns about the possibility that a lack of knowledge among both older patients and clinicians regarding the ageing process may contribute to age-related biased attributions, which may in turn be associated with typical biases in making these psychiatric diagnoses. Such a lack of knowledge may contribute to the attribution of debilitating clinical symptoms primarily to the ageing process, as if these symptoms are natural and "to be expected" in old age (Laidlaw and Pachana 2009). For some clinicians, this lack of knowledge likely also contributes to the difficulty in differentiating between signs of normal age-related deterioration and symptoms associated with treatable mental health problems. Finally, as later elaborated, paternalistic attitudes toward older adults and a view of these patients as incompetent may partially contribute to the problem of overuse of neuroleptic medications and reluctance to refer them for psychological or psychiatric treatments (Bronskill et al. 2004). Some of these typical biases may be evident in the following diagnoses.

Psychosis Distorted thinking and abnormal perceptual experiences are the hallmark symptoms of a primary psychotic disorder. These symptoms can also be concordant with conditions such as delirium, dementia, medication, and medical illness (Reinhardt and Cohen 2015), all of which can be relatively common in late life. Subsequent therapeutic decisions regarding psychotic symptoms require a high level of psychogeriatric-specific knowledge and a careful process of exclusion of potential causes. At the same time, a lack of psychogeriatric-specific knowledge, which may be reflected in ageist assumptions regarding older adults (e.g., "disturbed thinking in an older person means he or she have dementia"), can lead primary general practitioners to the misdiagnosis of psychotic syndromes by attributing these symptoms to dementia, rather than to a primary psychotic disorder. 
Depression In several past studies, the prevalence of depression in older adults was lower compared to younger adults (Blazer and Hybels 2005). However, a recent meta-analysis suggested that rates of depressive disorders increase dramatically in the oldest old compared to the young-old. For example, rates of depression among those 85 years and older were almost $25 \%$ higher compared with those $75-79$ years old, and 30 to 50\% higher among persons 90 years and over (Luppa et al. 2012). This inconsistency might be accounted for in several ways; one main factor might be problems in the diagnosis of depression in older adults. For example, evidence shows that compared to younger populations, a smaller percentage of older adults suffers from a major depressive disorder but a higher percentage experiences subsyndromal depressive symptoms (Meeks et al. 2011). Furthermore, in many cases, it can be difficult to distinguish between diagnosable depression, subsyndromal depressive states, and normal ageing among older adults (Fiske et al. 2009).

Part of this diagnostic conundrum may be due to differences in clinical presentation. For example, older adults who suffer from depressive symptoms may be less likely than younger adults to endorse sadness or low mood, or they may present primarily with less common symptoms such as apathy, possibly due to neurological changes (Alexopoulos et al. 2013). This phenomenon, known as "depression without sadness" or "masked depression" may lead to misdiagnosis (Covinsky et al. 2014). A lack of consensus on how to classify subsyndromal depressive symptoms or depressive presentations that are atypical may lead to misindentification of these syndromes (Ludvigsson et al. 2014). Furthermore, somatic elements which are prevalent in old age (e.g., physical disability, functional limitations, fatigue, digestive problems, and physical pain) may also cause emotional distress, leading to a clinical picture that, in some ways, resembles a depressive syndrome. We believe that a lack of knowledge about these changes in old age among both clinicians in geriatric mental health and patients may lead in some cases to overdiagnosis (and overtreatment, particularly with medication) of depression (Parmelee et al. 2013).

In addition, cognitive deficits may present as part of a psychiatric syndrome such as depression. Scholars have written extensively on "pseudo-dementia," a clinical presentation of depression distinguished by cognitive decline as the hallmark complaint (Burns and Jolley 2015). This syndrome is more common among older adults compared to younger adults, and assessment may be complicated by the presence of changes in cognition due to normal ageing or medication effects - both frequent among elderly patients (Lamberty and Bieliauskas 1993). In the case of pseudodementia, an emphasis by a clinician solely on the presentation of cognitive deterioration may reflect an ageist assumption that dementia is an unavoidable part of old age. At times this will result in the underdiagnosis of depression.

Anxiety Disorders Schuurmans and Balkom (2011) point to the fact that while there is a high prevalence of anxiety disorders in late life, these disorders are not easily diagnosed in older adults. The authors opine that older adults with anxiety use avoidance behaviors and thus run "under the radar" - resulting in significant underidentification and under-diagnosis. They explain the ability of older adults to avoid certain activities as being supported by the tendency of others to hold stereotypical 
views of older persons as incapable of completing tasks that require physical ability. They further note that family members have a tendency to aid the older adult by replacing him/her in performing these chores. This tendency may result from attitudes which are described by Palmore as "positive ageism", defined as attitudes toward older adults which may seem prosocial, but are, in essence, patronizing (Palmore et al. 2005). Schuurmans and Balkom (2011) also contend that ageism may be linked with a tendency to interpret anxiety and avoidance behaviors in late life (e.g., reluctance to leave the house, or to travel by bus) as adaptive or "realistic" reactions to age-related physical illnesses (e.g., arthritis affecting the person's mobility), or to life events (e.g., a previous fall on the street or on the bus). Moreover, the authors refer to the lack of knowledge about anxiety in late life among general practitioners, which makes it difficult for these clinicians to identify avoidance symptoms). They also note the fact that current diagnostic instruments may not identify the specific age-related factors of late-life anxiety disorders.

Another problem with anxiety disorders lies in the overlapping symptoms between Generalized Anxiety Disorder (GAD) and depression (Roy-Byrne and Wagner 2004). For example, fatigue and other physical symptoms, as well as negative ruminations, can be part of both syndromes. When GAD presents together with depression, primary care physicians tend to devaluate the persistent worries and to over-evaluate the negative mood, ending up with a diagnosis of depression (Calleo et al. 2009). Taken together, the evidence suggests that there is a lack of training in anxiety disorders in late-life and that these disorders are generally underindentified in clinical practice. We further suggest that the misdiagnosis of anxiety is related to a common stereotypical belief that old age is full of stressors and that older adults are "normally" distressed, worried, and avoidant.

Personality Disorders Personality disorders (PDs) were previously believed to be stable and unchanging conditions. However, it is unclear as to whether they are as stable across the life span as they were once assumed to be (Debast et al. 2014). In this respect, it is uncertain whether age-related changes in values and behaviors may be counted inappropriately as diagnostic symptoms of PD, or alternatively, whether these changes might conceal existing symptoms in a way that would disguise the existence of PDs. For example, studies have suggested that PDs may be manifested differently in later life compared to in younger adulthood due to cognitive decline, somatic comorbidities, and increased medication use (van Alphen et al., 2012).

In a recent study, older adults exhibited a higher level of avoidant personality symptoms compared to younger adults, yet showed lower levels of paranoid, schizoid, schizotypal, antisocial, borderline, histrionic, and narcissistic personality symptoms (Debast et al. 2014). This finding does not answer the question of whether current criteria for a PD diagnosis can be applied to older adults with clinical validity, or whether changes in these symptoms reflect a real change in the ways PDs are manifested in old age. In this vein, several items in diagnostic questionnaires have been reported to be less applicable for older adults compared to younger patients. For example, the item "avoids occupational activities", which is one of the 
criteria for avoidant PD, refers to a life domain that may be irrelevant in the assessment of a retired elderly person (Tackett et al. 2009). In a similar manner, the item "neither enjoys nor experiences sexual relations," which is one of the criteria for schizoid PD, may have a different relevance for younger versus older adults. These examples provide a glimpse into the numerous questions and challenges in assigning psychiatric diagnoses to older patients. Unfortunately, there is a dearth of literature in this area, despite the importance of personality in navigating the many changes and stressors of ageing. We suggest that the limited interest to date in studying age-related changes in PD stems from a narrow psychological perspective on human development. This perspective perceives adulthood as the end point of personality development and does not acknowledge late life as a stage in life which has an important effect on the individual's personality (in this respect, see Carstensen et al. 2011).

In summary, overdiagnosis, underdiagnosis, and misdiagnosis of the abovementioned diagnoses is related to the fact that diagnostic criteria and diagnostic tools have generally been normed on younger adults and may not be appropriate for use with older adults. Lack of knowledge and training represent additional factors. Finally, in some cases, ageist, stereotypical perceptions of older adults add to the difficulties in assessing psychiatric conditions in old age.

\subsection{Ageism in Treatment: Providing Psychotherapy to Older Persons}

In this subsection we aim at providing answers to the following questions: what are the adaptations required for psychotherapy with older adults, and what possible impact may negative age-related attitudes have on these adaptations? Are there specific age-related issues concerning the relationship between psychotherapists and older patients, and what is the potential effect of ageist attitudes of both partners on the therapeutic relationship? What is the possible effect of ageist attitudes on the implementation of interventions for mental health problems which are common in old age?

\subsubsection{Attitudes and Adaptations in Psychotherapy with Older Patients}

When working with older patients, certain adaptations can make almost any therapeutic approach more effective in reaching treatment goals. At the same time, agebased prejudice and discrimination can impact the provider-patient relationship and hinder the therapeutic work. When working with an elderly patient, for example, there may be a greater likelihood of encountering difficulties with transportation to 
appointments, medical health symptoms, conflicts with care-giving obligations, and financial constraints. These difficulties may activate stereotyped and ageist attitudes on the part of the psychotherapist. If the psychotherapist follows Freud's view (1905/1953) on therapy in old age, and perceives older adults as passive, rigid, stubborn, unwilling to invest efforts in changing, or as lacking the flexibility required to engage in psychotherapy, he or she may view these barriers not as problems to be solved in order to continue in psychotherapy, but as resistance on the part of the patient. Such a stance by the psychotherapist may be perceived as an insult by a patient who is facing these serious difficulties (Wyman et al. 2011). Ageist attitudes may also impede the flexibility of psychotherapists to consider relevant issues of access to psychotherapy and psychotherapy location, session's length and continuity. Therefore, psychotherapists may fail in adapting the psychotherapy to settings which are more available for older patients (e.g., primary care medicine settings, adult day health centers). When the patient is a frail older adult, ageist attitudes which attribute communication problems only to cognitive impairment (e.g., "all older adults are senile and confused") might hinder psychotherapists in taking steps toward helpful adaptations for working with such patients (e.g., audiotaping therapy sessions for review at home, ensuring good lighting in the therapy room, slowing the pace of speech and lowering the tone of voice, etc. See Wyman et al. 2011).

\subsubsection{Psychotherapists' and Patients'Ageist Attitudes and the Therapeutic Relationship}

Psychotherapists and patients might bring into the therapeutic relationship responses that were learnt in other interpersonal contexts. Knight (2004) suggests that the terms "transference" (the feelings and thoughts the patient has about the psychotherapist) and "countertransference" (the feelings and thoughts the psychotherapist has about the patient) can be used to understand how age-related stigmas affect the psychotherapeutic relationship with older patients. Stereotypes and attitudes related to age can affect the internal representations each party establishes regarding the other, which are not based on real people or on what really happens in therapy (Knight 2004). On both sides of the psychotherapeutic relationship, age-biased attitudes can impact how the other is viewed.

Psychotherapists may adhere to stereotypes pertaining to the age group of older frail adults and fail to acknowledge the strengths and resources of these patients. In some cases, the psychotherapist might interact with the patient as a parent or a grandparent figure. This may lead to overcautious and unassertive approaches by the therapist during the course of psychotherapy. Moreover, when working with an older patient, psychotherapists may overlook erotic transference or react to it negatively, as erotic transference contradicts society's ageist perceptions about sexuality in old age (Wyman et al. 2011). Older patients may stigmatically define their psychotherapist as belonging to an age group of younger and healthy adults, who 
"knows nothing about the experience of being old and frail." They might also relate to a younger psychotherapist as a child or grandchild, and not acknowledge his or her professional abilities (Knight 2004). These transference and counter-transference attitudes are based on negative age-related biases which likely have a negative impact on therapeutic outcome.

\subsubsection{Ageist Attitudes and Specific Psychotherapeutic and Drug Interventions in Old Age}

Geriatric mental health scholars agree that evidence-based psychotherapy approaches (e.g., cognitive-behavioral therapy, interpersonal therapy, problem solving therapy) are appropriate and effective for use with older adult patients, with some adaptations (Wyman et al. 2011). An in-depth review of these approaches is beyond the scope of this chapter. However, a brief discussion of the effects of ageist attitudes on the implementation of therapies for mental disorder with older patients is in order. We will then relate to the possible impact of physicians' ageist attitudes on their tendency for overuse of psychiatric medications in older adults.

Cognitive behavioral therapy (Beck 1995) is effective for older adults suffering from depression (Arean and Cook 2002) and anxiety (Nordhus and Pallesen 2003). However, an ageist approach which perceives older patients as generally frail and incompetent may cause the psychotherapist to assign fewer tasks for patients to complete between therapy sessions, though these "homework assignments" are considered fundamental to treatment success in this modality. In addition, when the psychotherapist's stereotypical, and likely subconscious, beliefs about the elderly (e.g., "older adults who are not working, are a societal burden") correspond to automatic maladaptive thoughts held by the patient (e.g., "As a retired worker, I'm no use anymore"), it is quite challenging for a psychotherapist to identify these maladaptive thoughts and engage the patient in correcting them.

Interpersonal therapy also has a strong evidence base for use with older persons (Arean and Cook 2002) and focuses on symptom relief and on the improvement of interpersonal coping strategies in depression (Klerman et al. 1984). However, it may be difficult for a psychotherapist who perceives older patients as incompetent, disabled, and inflexible to acknowledge the changes that come with age, in their patients' social roles within the family and work environment, to understand the impact of the loss of loved ones, or to be aware of potential intergenerational conflicts that may exist for the patient (Wyman et al. 2011). Such stereotypical attitudes toward ageing can hinder the psychotherapist's insight into these issues and pose a real threat to the effectiveness of interpersonal therapy.

In problem-solving therapy, which views a deficit in problem-solving skills as one of the causes for depression, the psychotherapist and patient work together to identify problems patients are currently facing and solve them in a series of standard steps (Nezu et al. 1988). However, the implementation of this form of therapy with 
older adults requires the understanding that a number of problems which present in later life are not "solvable" in the commonly-understood sense. For example, some illnesses cannot be cured, and the loss of close relatives and friends cannot be reversed. It may be difficult for a psychotherapist who does not accept his or her own ageing to assist patients to effectively accept these inevitabilities and apply the therapeutic tools to problems that can be effectively managed to improve mood. Here too, negative beliefs about old age as a time of resignation, slowed or absent personal growth and passivity might block the psychotherapist's ability to most effectively work with this therapeutic approach.

Psychotherapeutic treatment, or "talk therapy," is not the only mental health treatment approach that is impacted by ageism. The overuse of psychiatric medication in older adults is well documented in the literature and is a rising concern (for a review, see Ruxton et al. 2015; see also Fialova and colleagues in this volume). This tendency is pronounced in long-term care facilities, where a particularly high consumption is reported for benzodiazepines, antipsychotics and antidepressants (Anrys et al. 2016). These trends continue despite clear evidence of the heightened risks of certain medications for the elderly - including accidents and falls, cognitive impairment, and a development of tolerance and addiction to these drugs - and despite the existence of evidence-based guidelines for prescribing (Schuurmans and Balkom 2011).

According to some researchers system-based ageist attitudes (e.g. perceiving older adults as "beyond help", "useless", or perhaps undeserving of equal attention to quality mental health care) plays a role in maintaining the gap between best practice and reality (Kolanowski et al. 2009). For example, one qualitative study on the use of non-pharmacological interventions in nursing homes identified the typical reduced evening and weekend staffing patterns, and the resultant time pressure on personnel, as a significant barrier to using behavioral approaches to address problem behaviors versus medications (Kolanowski et al. 2009). These authors concluded that a culture change related to use of medication in older patients is necessary, noting that successful use of nonpharmacological interventions requires "the right staff with the right education at the right time" (p. 1). Similar concerns have also been demonstrated in primary care settings (Cook et al. 2007) and relate to impatience of primary doctors and nurses, who may quickly opt to use benzodiazepines when faced with agitated behaviors in an older person (Ayalon et al. 2013). Medications require less effort and less time, and are more cost-effective for the medical system, at least in the short term.

A second reason for the frequent use of medications to treat mental disorder is related to the belief that "older patients don't want psychotherapy." This is a widelyheld misconception, despite the evidence for a "positive cohort shift" in the attitudes of healthy older adults to seek help for mental health difficulties (Woodward and Pachana 2009) and evidence to the contrary from large-scale clinical trials (Gum et al. 2006). We argue that age stereotypes play a role in perpetuating this misconception, and that addressing ageism needs to be part of the culture change away from overuse of medications and toward increased use of behavioral interventions for older patients. 


\subsubsection{Recommendations for Mental Health Clinicians}

In summary, the assessment and treatment of older adults within the mental health setting presents many challenges even to seasoned clinicians. These challenges include complicated symptom presentations, inadequate professional training and exposure to geriatric syndromes and psychiatric conditions in late life and a limited set of assessment tools which are appropriate and valid for use with older patients. Psychotherapy with older adults is frequently less straightforward and requires adaptations of commonly used therapeutic approaches to address the unique problems and difficulties faced in the later years in order to maximize the chances of therapeutic success.

Ageism presents another important, though often overlooked, challenge. Ageist attitudes of both patients and psychotherapists present as transference and countertransference phenomena. Ageist attitudes of the psychotherapists can interact in various ways with different methods of therapy which are used for treating older adults. When adapting different methods of therapy to older adults, psychotherapists should strive to identify their own ageist biases which may be at play and to remain flexible in adapting their approach.

In order to neutralize the effect of ageist attitudes, professionals working with older adults should first strive to understand the meaning of "ageing" and "old age" for their older patients as well as for themselves. They should reflect on their own attitudes toward the ageing of loved ones and themselves, and become aware of the ways in which they want to be seen by their older patients (Wyman et al. 2011). Psychotherapists also need to be able to acknowledge not only the weaknesses but also the strengths of older patients. Ageist attitudes may lead psychotherapists to ignore internal and external resources and to focus only on the patients' shortcomings. Such an attitude may cause psychotherapists to perceive their older patients as more helpless than they truly are, and is compatible with the tendency described by Palmore as "positive ageism": an attitude toward older adults which may seem (in this case - to the psychotherapist) as beneficial, but is, in essence, patronizing (Palmore et al. 2005).

Further, we strongly encourage professionals to directly address age-related stigmas, including self-ageism and "self-double stigmatization" and misperceptions with their older patients. For example, a mental health provider might raise ideas related to stigmatization of mental illness and therapy with their patients for discussion (for example, the common concern that "receiving therapy means I'm weak"), as well as age-related stigmas (e.g., "younger psychotherapists will never understand me"; "I'm too old to change"). A mental health clinician can encourage the patient to express these concerns by being proactive and raising frequently asked questions, and can provide written educational materials addressing these issues. Addressing age- and mental illness-related stigmas with patients can increase older patients' attendance and engagement in psychotherapy, regardless of the therapeutic approach (Wyman et al. 2011). 


\subsection{General Conclusions and Recommendations}

In this chapter, we have explored how negative ageist attitudes on the part of both mental health care providers and older patients may contribute to challenges in the diagnosis and psychotherapy of mental disorders in older adults. We note the inherent challenges in diagnosis and therapy of mental disorders in older adults, which are due to complex clinical presentations and comorbidities. We argue that - in general - mental health clinicians continue to be less equipped to work and do psychotherapy with older adults compared with younger adults, hold generally negative assumptions about older adults as psychiatric patients and lack adequate professional knowledge of the geriatric population. In addition, internalized ageism (selfdouble stigmatization) impacts the interactions of older patients with the mental health care system and can contribute to a reluctance to seek mental health care services.

Changing these attitudes and misconceptions requires a combined effort of both governments and mental health clinicians. Governments have to allocate more financial resources for mental health services for older adults and for geriatric training and education for both providers and consumers of mental health care. In this regard, several specific recommendations for mental health clinicians can be made: (1) Providers should be supported in seeking out appropriate training on working with older adults and the developmental changes that occur in late life. Training programs that acknowledge the uniqueness of the older adult population are needed, especially in countries without a presence of the psychogeriatric field (e.g., Israel, as of this writing).

(2) Scientific study is needed to ensure that mental health diagnostic criteria and available assessment instruments are valid for use with older adults. (3) Further scientific investigation is also required for the adaptation of therapies for use with older adults. (4) Mental health clinicians will benefit from self-reflection to increase awareness of ageist attitudes which impact their work with older patients. (5) Improved collaboration and an exchange of knowledge among health professions in the field of gerontology (e.g., occupational therapists, physiotherapists, psychologists, psychiatrists and psychogeriatricians) can improve assessment and therapeutic abilities.

As for the elderly consumers of mental health care services, several steps can be done in order to change their negative views about the ageing process and about mental health services: (1) Patients' education about the benefits of mental health psychotherapy at all ages, and about effective engagement in mental health services might increase the use of psychological and psychiatric therapy for older adults. (2) Psychoeducation for older mental health patients could help to reduce self-ageism among this patient group.

In conclusion, we agree with other authors in this volume (e.g., Wyman et al., Fialova et al., Gweyrtz-Meydan et al., Evans) that addressing ageism within health care is vital in improving services and achieving optimal treatment outcomes. We believe that, while mitigating ageism among mental health clinicians, older mental 
health patients, and their family members and friends may not add years to their lives, it can add lives to their years - which might be even more important.

\section{References}

Alexopoulos, G. S., Hoptman, M. J., Yuen, G., Kanellopoulos, D., Seirup, J. K., Lim, K. O., \& Gunning, F. M. (2013). Functional connectivity in apathy of late-life depression: A preliminary study. Journal of Affective Disorders, 149(1), 398-405. https://doi.org/10.1016/j. jad.2012.11.023

American Psychological Association, Center for Workforce Studies. (2015). 2015: APA member profiles. Retrieved from http://www.apa.org/workforce/publications/15-member/profiles.pdf

Anrys, P., Strauven, G., Boland, B., Dalleur, O., Declercq, A., Degryse, J. M., et al. (2016). Collaborative approach to optimise MEdication use for older people in nursing homes (COME-ON): Study protocol of a cluster controlled trial. Implementation Science, 11(35), 1-11. https://doi.org/10.1186/isrctn66138978

Apesoa-Varano, E. C., Barker, J. C., Unutzer, J., Aguilar-Gaxiola, S., Johnson, M. D., Tran, C., et al. (2015). Idioms of distress among depressed white-non-Mexican and Mexican-origin older men. Journal of Cross-Cultural Gerontology, 30(3), 305-318. https://doi.org/10.1007/ s10823-015-9267-8

Arean, P. A., \& Cook, B. L. (2002). Psychotherapy and combined psychotherapy/pharmacotherapy for late life depression. Biological Psychiatry, 52(3), 293-303. https://doi.org/10.1016/ s0006-3223(02)01371-9

Ayalon, L., Gross, R., Yaari, A., Feldhamer, E., Balicer, R. D., \& Goldfracht, M. (2013). Patients' and physicians' characteristics associated with the purchase of benzodiazepines by older primary care patients in Israel. Administration and Policy in Mental Health and Mental Health Services Research, 40(2), 117-123. https://doi.org/10.1007/s10488-011-0381-9

Ayalon, L., Karkabi, K., Bleichman, I., Fleischmann, S., \& Goldfracht, M. (2016). Barriers to the treatment of mental illness in primary care clinics in Israel. Administration and Policy in Mental Health and Mental Health Services Research, 43(2), 231-240. https://doi.org/10.1007/ s10488-015-0634-0

Barnow, S., Linden, M., Lucht, M., \& Freyberger, H. J. (2004). Influence of age of patients who wish to die on treatment decisions by physicians and nurses. The American Journal of Geriatric Psychiatry, 12(3), 258-264. https://doi.org/10.1176/appi.ajgp.12.3.258

Barrett, A. E., \& Robbins, C. (2008). The multiple sources of women's ageing anxiety and their relationship with psychological distress. Journal of Ageing and Health, 20(1), 32-65. https:// doi.org/10.1177/0898264307309932

Beck, J. S. (1995). Cognitive therapy: Basics and beyond. New York: Guilford. https://doi. org/10.1037/000344

Benedict, A. (1995). Attributions of causes for chronic illness among aged persons. Activities, Adaptation \& Ageing, 19(4), 49-59. https://doi.org/10.1300/j016v19n04_04

Blazer, D. (1989). Depression in the elderly. New England Journal of Medicine, 320(3), 164-166. https://doi.org/10.1056/nejm198901193200306

Blazer, D. G. (2003). Depression in late life: Review and commentary. The Journals of Gerontology Series A: Biological Sciences and Medical Sciences, 58(3), M249-M265. https:// doi.org/10.1176/foc.7.1.foc118

Blazer, D. G., \& Hybels, C. F. (2005). Origins of depression in later life. Psychological Medicine, 35(09), 1241-1252. https://doi.org/10.1017/s0033291705004411

Boardman, F., Griffiths, F., Kokanovic, R., Potiriadis, M., Dowrick, C., \& Gunn, J. (2011). Resilience as a response to the stigma of depression: A mixed methods analysis. Journal of Affective Disorders, 135(1-3), 267-276. https://doi.org/10.1016/j.jad.2011.08.007 
Bodner, E., Shrira, A., Bergman, Y. S., \& Cohen-Fridel, S. (2015a). Anxieties about ageing and death and psychological distress: The protective role of emotional complexity. Personality and Individual Differences, 83, 91-96. https://doi.org/10.1016/j.paid.2015.03.052

Bodner, E., Shrira, A., Bergman, Y. S., Cohen-Fridel, S., \& Grossman, E. S. (2015b). The interaction between ageing and death anxieties predicts ageism. Personality and Individual Differences, 86, 15-19. https://doi.org/10.1016/j.paid.2015.05.022

Bouman, W. P., \& Arcelus, J. (2001). Are psychiatrists guilty of 'ageism'when it comes to taking a sexual history? International Journal of Geriatric Psychiatry, 16(1), 27-31. https://doi. org/10.1002/1099-1166(200101)16:1<27::aid-gps267>3.3.co;2-j

Britton, P. G., \& Woods, R. T. (1996). Introduction. In R. T. Woods (Ed.), Handbook of the clinical psychology of ageing (pp. 1-14). Chichester: Wiley. https://doi.org/10.1002/9780470773185

Bronskill, S. E., Anderson, G. M., Sykora, K., Wodchis, W. P., Gill, S., Shulman, K. I., \& Rochon, P. A. (2004). Neuroleptic drug therapy in older adults newly admitted to nursing homes: Incidence, dose, and specialist contact. Journal of the American Geriatrics Society, 52(5), 749-755. https://doi.org/10.1111/j.1532-5415.2004.52212.x

Bryant, C., \& Koder, D. (2015). Why psychologists do not want to work with older adults-and why they should.... International Psychogeriatrics, 27(03), 351-354. https://doi.org/10.1017/ s1041610214002208

Bryant, C., Bei, B., Gilson, K., Komiti, A., Jackson, H., \& Judd, F. (2012). The relationship between attitudes to ageing and physical and mental health in older adults. International Psychogeriatrics, 24(10), 1674-1683. https://doi.org/10.1017/s1041610212000774

Burns, A., \& Jolley, D. (2015). Pseudodementia: History, mystery and positivity. In D. Bhugra \& G. S. Malhi (Eds.), Troublesome disguises: Manageing challenging disorders in psychiatry (pp. 218-230). West Sussex: Wiley. https://doi.org/10.1002/9781118799574

Butler, R. N. (1975). Psychiatry and the elderly: An overview. The American Journal of Psychiatry, 132(9), 893-900. https://doi.org/10.1176/ajp.132.9.893

Buttigieg, S., Ilinca, S., Jose, M. S., \& Larsson, A. T. (2018). Researching ageism in health-care and long term care. In L. Ayalon \& C. Tesch-Römer (Eds.), Contemporary perspectives on ageism: Vol. 19. International perspectives on aging (pp. 491-513). Berlin: Springer.

Calleo, J., Stanley, M. A., Greisinger, A., Wehmanen, O., Johnson, M., Novy, D., Wilson, N., \& Kunik, M. (2009). Generalized anxiety disorder in older medical patients: Diagnostic recognition, mental health management and service utilization. Journal of Clinical Psychology in Medical Settings, 16(2), 178-185. https://doi.org/10.1007/s10880-008-9144-5

Carstensen, L. L., Turan, B., Scheibe, S., Ram, N., Ersner-Hershfield, H., Samanez-Larkin, G. R., Brooks, K. P., \& Nesselroade, J. R. (2011). Emotional experience improves with age: Evidence based on over 10 years of experience sampling. Psychology and ageing, 26(1), 21-33. https:// doi.org/10.1037/a0021285

Chachamovich, E., Fleck, M., Laidlaw, K., \& Power, M. (2008). Impact of major depression and subsyndromal symptoms on quality of life and attitudes toward ageing in an international sample of older adults. The Gerontologist, 48(5), 593-602. https://doi.org/10.1093/geront/48.5.593

Cook, J. M., Marshall, R., Masci, C., \& Coyne, J. C. (2007). Physicians' perspectives on prescribing benzodiazepines for older adults: A qualitative study. Journal of General Internal Medicine, 22(3), 303-307. https://doi.org/10.1007/s11606-006-0021-3

Covinsky, K. E., Cenzer, I. S., Yaffe, K., O’Brien, S., \& Blazer, D. G. (2014). Dysphoria and anhedonia as risk factors for disability or death in older persons: Implications for the assessment of geriatric depression. The American Journal of Geriatric Psychiatry, 22(6), 606-613. https:// doi.org/10.1016/j.jagp.2012.12.001

Debast, I., van Alphen, S. P., Rossi, G., Tummers, J. H., Bolwerk, N., Derksen, J. J., \& Rosowsky, E. (2014). Personality traits and personality disorders in late middle and old age: Do they remain stable? A literature review. Clinical Gerontologist, 37(3), 253-271. https://doi.org/10. 1080/07317115.2014.885917 
DiNapoli, E. A., Cully, J. A., Mott, J. M., Hundt, N. E., Mignogna, J., Sansgiry, S., Yu, H. J., Trahan, L. H., \& Kunik, M. E. (2015). Mental health utilization among older veterans with coexisting depression and dementia. SAGE Open Medicine, 3, 1-6.

Dye, C. J. (1978). Psychologists' role in the provision of mental health care for the elderly. Professional Psychology, 9(1), 38-49. https://doi.org/10.1177/2050312114566488

Dolberg, P. H., Sigurðardóttir, S., \& Trummer, U. (2018). Ageism and older immigrants. In L. Ayalon \& C. Tesch-Römer (Eds.), Contemporary perspectives on ageism: Vol. 19. International perspectives on aging (pp. 177-191). Berlin: Springer.

Eisner, R. J., Quinn, M. E., Fanning, S. D., Gueldner, S. H., \& Poon, L. W. (1999). Ethical and policy considerations for centenarians-the oldest old. Image: The Journal of Nursing Scholarship, 31(3), 263-267. https://doi.org/10.1111/j.1547-5069.1999.tb00495.x

Elsner, R. J. (2002). Changes in eating behavior during the aging process. Eating Behaviors, 3(1), 15-43. https://doi.org/10.1016/s1471-0153(01)00041-1

Fiske, A., Wetherell, J. L., \& Gatz, M. (2009). Depression in older adults. Annual Review of Clinical Psychology, 5, 363-389. https://doi.org/10.1146/annurev.clinpsy.032408.153621

Ford, C. V., \& Sbordone, R. J. (1980). Attitudes of psychiatrists toward elderly patients. The American Journal of Psychiatry, 137(5), 571-575. https://doi.org/10.1176/ajp.137.5.571

Freud, S. (1953). On psychotherapy. In The complete works of Sigmund Freud (J. Strachey, Trans., Vol. 6, pp. 249-263). London: Hogarth. (Original work published 1905).

Fung, K. M., Tsang, H. W., Corrigan, P. W., Lam, C. S., \& Cheng, W. M. (2007). Measuring selfstigma of mental illness in China and its implications for recovery. International Journal of Social Psychiatry, 53(5), 408-418. https://doi.org/10.1177/0020764007078342

Gonçalves, D. C., Guedes, J., Fonseca, A. M., Pinto, F. C., Martín, I., Byrne, G. J., \& Pachana, N. A. (2011). Attitudes, knowledge, and interest: Preparing university students to work in an ageing world. International Psychogeriatrics, 23(02), 315-321. https://doi.org/10.1017/ s1041610210001638

Gum, A. M., Arean, P. A., Hunkeler, E., Tang, L., Katon, W., Hitchcock, P., et al. (2006). Depression treatment preferences in older primary care patients. Gerontologist, 46(1), 14-22. https://doi. org/10.1176/appi.psy.48.6.482

Halpain, M. C., Harris, M. J., McClure, F. S., \& Jeste, D. V. (1999). Training in geriatric mental health: Needs and strategies. Psychiatric Services, 59(9), 1205-1208. https://doi.org/10.1176/ ps.50.9.1205

Helmes, E., \& Gee, S. (2003). Attitudes of Australian therapists toward older clients: Educational and training imperatives. Educational Gerontology, 29(8), 657-670. https://doi. org/10.1080/03601270390225640

Hendrie, H. C., Callahan, C. M., Levitt, E. E., Hui, S. L., Mustek, B., Austrom, M. G., Numberger, J. I., \& Tierney, W. M. (1995). Prevalence rates of major depressive disorders: The effects of varying the diagnostic criteria in an older primary care population. The American Journal of Geriatric Psychiatry, 3(2), 119-131. https://doi.org/10.1097/00019442-199500320-00004

Huy, C., Schneider, S., \& Thiel, A. (2010). Perceptions of ageing and health behaviour: Determinants of a healthy diet in an older German population. The Journal of Nutrition, Health and Ageing, 14(5), 381-385. https://doi.org/10.1007/s12603-010-0084-z

Ingram, R. E., \& Luxton, D. D. (2005). Vulnerability-stress models. In B. L. Hankin \& J. R. Z. Abela (Eds.), Development of psychopathology: A vulnerability-stress perspective (pp. 32-46). Los Angeles: Sage. https://doi.org/10.4135/9781452231655.n2

Karel, M. J., Gatz, M., \& Smyer, M. A. (2012). Ageing and mental health in the decade ahead: What psychologists need to know. American Psychologist, 67(3), 184-198. https://doi. org/10.1037/a0025393

Kessler, E. M., \& Bowen, C. E. (2015). Resilience. The Encyclopedia of Adulthood and Ageing, 3(1), 1213-1216. https://doi.org/10.1002/9781118521373.wbeaa231

Klerman, G. L., Weissman, M. M., Rounsaville, B., \& Chevron, E. (1984). Interpersonal psychotherapy for depression. New York: Basic Books. 
Knight, B. G. (2004). Transference and counter transference in older adlts. In B. G. Knight (Ed.), Psychotherapy with older adults (pp. 60-77). Los Angeles: Sage Publications. https://doi. org/10.4135/9781452204574

Koder, D. A., \& Helmes, E. (2008). Predictors of interest in working with older adults: A survey of postgraduate trainee psychologists. Gerontology \& Geriatrics Education, 29(2), 158-171. https://doi.org/10.1080/02701960802223233

Kolanowski, A., Fick, D., Frazer, C., \& Penrod, J. (2009). It's about time: Use of nonpharmacological interventions in the nursing home. Journal of Nursing Scholarship, 42(2), 214-222. https://doi.org/10.1111/j.1547-5069.2010.01338.x

Krekula, C., Nikander, P., \& Wilińska, M. (2018). Multiple marginalizations based on age: gendered ageism and beyond. In L. Ayalon \& C. Tesch-Römer (Eds.), Contemporary perspectives on ageism: Vol. 19. International perspectives on aging (pp. 33-50). Berlin: Springer.

Laidlaw, K., \& Pachana, N. A. (2009). Ageing, mental health, and demographic change: Challenges for psychotherapists. Professional Psychology: Research and Practice, 40(6), 601-608. https:// doi.org/10.1037/a0017215

Lamberty, G. J., \& Bieliauskas, L. A. (1993). Distinguishing between depression and dementia in the elderly: A review of neuropsychological findings. Archives of Clinical Neuropsychology, 8(2), 149-170. https://doi.org/10.1016/0887-6177(93)90032-v

Lee, K. M., Volans, P. J., \& Gregory, N. (2003). Attitudes towards psychotherapy with older people among trainee clinical psychologists. Ageing \& Mental Health, 7(2), 133-141. https://doi. org/10.1080/1360786031000072303

Lerner, Y., \& Levinson, D. (2012). Who gets mental health treatment from the GP? Results from the Israel National Epidemiological Mental Health Survey. Family Practice, 29(5), 561-566. https://doi.org/10.1093/fampra/cms017

Levy, B. R. (2003). Mind matters: Cognitive and physical effects of ageing self-stereotypes. The Journals of Gerontology Series B: Psychological Sciences and Social Sciences, 58(4), 203211. https://doi.org/10.1093/geronb/58.4.p203

Levy, B. R., \& Myers, L. M. (2004). Preventive health behaviors influenced by self-perceptions of aging. Preventive Medicine, 39(3), 625-629. https://doi.org/10.1016/j.ypmed.2004.02.029

Levy, B. R., Pilver, C. E., \& Pietrzak, R. H. (2014). Lower prevalence of psychiatric conditions when negative age stereotypes are resisted. Social Science \& Medicine, 119, 170-174. https:// doi.org/10.1016/j.socscimed.2014.06.046

Ludvigsson, M., Milberg, A., Marcusson, J., \& Wressle, E. (2014). Normal ageing or depression? A qualitative study on the differences between subsyndromal depression and depression in very old people. The Gerontologist, 55(5), 760-769. https://doi.org/10.1093/geront/gnt162

Luppa, M., Sikorski, C., Luck, T., Ehreke, L., Konnopka, A., Wiese, B., Weyerer, S., König, H. H., \& Riedel-Heller, S. G. (2012). Age-and gender-specific prevalence of depression in latest-lifesystematic review and meta-analysis. Journal of Affective Disorders, 136(3), 212-221. https:// doi.org/10.1016/j.jad.2010.11.033

Mackin, R. S., \& Areán, P. A. (2007). Cognitive and psychiatric predictors of medical treatment adherence among older adults in primary care clinics. International Journal of Geriatric Psychiatry, 22(1), 55-60. https://doi.org/10.1002/gps.1653

McKinney, B. C., \& Sibille, E. (2013). The age-by-disease interaction hypothesis of late-life depression. The American Journal of Geriatric Psychiatry, 21(5), 418-432. https://doi. org/10.1097/jgp.0b013e31826ce80d

Meeks, T. W., Vahia, I. V., Lavretsky, H., Kulkarni, G., \& Jeste, D. V. (2011). A tune in "a minor" can "b major": A review of epidemiology, illness course, and public health implications of subthreshold depression in older adults. Journal of Affective Disorders, 129(1), 126-142. https:// doi.org/10.1016/j.jad.2010.09.015

Milaneschi, Y., \& Penninx, B. W. J. H. (2014). Depression in older persons with mobility limitations. Current Pharmaceutical Design, 20(19), 3114-3118. https://doi.org/10.2174/13816128 113196660060 
Nezu, A. M., Nezu, C. M., \& Perri, M. G. (1988). Problem solving therapy for depression. New York: Wiley-Interscience.

Nordhus, J. H., \& Pallesen, S. (2003). Psychological treatment of late-life anxiety: And empirical review. Journal of Consulting and Clinical Psychology, 71(4), 643-651. https://doi. org/10.1037/0022-006x.71.4.643

Owens, K. M. B., Hadjistavropoulos, T., \& Asmundson, G. J. G. (2000). Addressing the need for appropriate norms when measuring anxiety in seniors. Aging \& Mental Health, 4(4), 309-314. https://doi.org/10.1080/713649964

Palgi, Y. (2015). Predictors of the new criteria for probable PTSD among older adults. Psychiatry Research, 230, 777-782. https://doi.org/10.1016/j.psychres.2015.11.006

Palmore, E. B., Branch, L., \& Harris, D. (Eds.). (2005). Encyclopedia of ageism. Binghamton: Haworth Press. https://doi.org/10.4324/9781315043975

Parmelee, P. A., Harralson, T. L., McPherron, J. A., \& Schumacher, H. R. (2013). The structure of affective symptomatology in older adults with osteoarthritis. International Journal of Geriatric Psychiatry, 28(4), 393-401. https://doi.org/10.1002/gps.3837

Petersen, R. C. (2004). Mild cognitive impairment as a diagnostic entity. Journal of Internal Medicine, 256(3), 183-194. https://doi.org/10.1111/j.1365-2796.2004.01388.x

Pietrzak, R. H., Goldstein, R. B., Southwick, S. M., \& Grant, B. F. (2012). Physical health conditions associated with posttraumatic stress disorder in US older adults: Results from wave 2 of the National Epidemiologic Survey on alcohol and related conditions. Journal of the American Geriatrics Society, 60(2), 296-303. https://doi.org/10.1111/j.1532-5415.2011.03788.x

Poon, C. Y., \& Knight, B. G. (2009). Influence of sad mood and old age schema on older adults' attention to physical symptoms. The Journals of Gerontology Series B: Psychological Sciences and Social Sciences, 64((1), 41-44. https://doi.org/10.1093/geronb/gbn025

Qualls, S. H., Segal, D. L., Norman, S., Niederehe, G., \& Gallagher-Thompson, D. (2002). Psychologists in practice with older adults: Current patterns, sources of training, and need for continuing education. Professional Psychology: Research and Practice, 33(5), 435-442. https://doi.org/10.1037//0735-7028.33.5.

Ray, D. C., McKinney, K. A., \& Ford, C. V. (1987). Differences in psychologists' ratings of older and younger clients. The Gerontologist, 27(1), 82-86. https://doi.org/10.1093/geront/27.1.82

Reinhardt, M. M., \& Cohen, C. I. (2015). Late-life psychosis: Diagnosis and treatment. Current Psychiatry Reports, 17(2), 1-13. https://doi.org/10.1007/s11920-014-0542-0

Richards, S., Donovan, S., Victor, C., \& Ross, F. (2007). Standing secure amidst a falling world? Practitioner understandings of old age in responses to a case vignette. Journal of Interprofessional Care, 21(3), 335-349. https://doi.org/10.1080/13561820701289352

Roy-Byrne, P. P., \& Wagner, A. (2004). Primary care perspectives on generalized anxiety disorder. The Journal of Clinical Psychiatry, 65(suppl 13), 20-26.

Rush, N., Angermeyer, M. C., \& Corrigan, P. W. (2005). Mental illness stigma: Concepts, consequences, and initiatives to reduce stigma. European Psychiatry, 20(8), 529-539. https://doi. org/10.1016/j.eurpsy.2005.04.004

Ruxton, K., Woodman, R. J., \& Mangoni, A. A. (2015). Drugs with anticholinergic effects and cognitive impairment, falls and all-cause mortality in older adults: A systematic review and metaanalysis. British Journal of Clinical Pharmacology, 80(2), 209-220. https://doi.org/10.1111/ bcp. 12617

Schuurmans, J., \& van Balkom, A. (2011). Late-life anxiety disorders: A review. Current Psychiatry Reports, 13(4), 267-273. https://doi.org/10.1007/s11920-011-0204-4

Scott, A., \& Bhutani, G. (1999). Career choices and attitudes to the older adult specialty. Clinical Psychology Forum, 126, 11-15.

Shmotkin, D., Eyal, N., \& Lomranz, J. (1992). Motivations and attitudes of clinical psychologists regarding treatment of the elderly. Educational Gerontology: An International Quarterly, 18(2), 177-192. https://doi.org/10.1080/0360127920180205

Sternbach, H. (1998). Age-associated testosterone decline in men: Clinical issues for psychiatry. American Journal of Psychiatry, 155(10), 1310-1318. https://doi.org/10.1176/ajp.155.10.1310 
Tackett, J. L., Balsis, S., Oltmanns, T. F., \& Krueger, R. F. (2009). A unifying perspective on personality pathology across the life span: Developmental considerations for the fifth edition of the diagnostic and statistical manual of mental disorders. Development and Psychopathology, 21(03), 687-713. https://doi.org/10.1017/s095457940900039x

Uncapher, H., \& Areán, P. A. (2000). Physicians are less willing to treat suicidal ideation in older patients. Journal of the American Geriatrics Society, 48, 188-192. https://doi. org/10.1111/j.1532-5415.2000.tb03910.x

Van Alphen, S. P. J., Bolwerk, N., Videler, A. C., Tummers, J. H. A., Van Royen, R. J. J., Barendse, H. P. J., et al. (2012). Age-related aspects and clinical implications of diagnosis and treatment of personality disorders in older adults. Clinical Gerontologist, 35(1), 27-41. https://doi.org/1 0.1080/07317115.2011.628368

Voss, P., Bodner, E., \& Rothermund, K. (2018). Ageism: The relationship between age stereotypes and age discrimination. In L. Ayalon \& C. Tesch-Römer (Eds.), Contemporary perspectives on ageism: Vol. 19. International perspectives on aging (pp. 11-32). Berlin: Springer.

Weiss, D., \& Lang, F. R. (2012). "They" are old but "I" feel younger: Age-group dissociation as a self-protective strategy in old age. Psychology and Ageing, 27(1), 153-163. https://doi. org/10.1037/a0024887

Werner, P., Stein-Shvachman, I., \& Heinik, J. (2009). Perceptions of self-stigma and its correlates among older adults with depression: A preliminary study. International Psychogeriatrics, 21(06), 1180-1189. https://doi.org/10.1017/s1041610209990470

Whitbourne, S. K., \& Krauss, S. (2011). Central nervous system. In S. K. Whitbourne (Ed.), The aging body: Physiological changes and psychological consequences (pp. 125-149). New York: Springer.

Woodward, R., \& Pachana, N. A. (2009). Attitudes towards psychological treatment among older Australians. Australian Psychologist, 44(2), 86-93. https://doi. org/10.1080/00050060802583610

Wurm, S., \& Benyamini, Y. (2014). Optimism buffers the detrimental effect of negative selfperceptions of ageing on physical and mental health. Psychology \& Health, 29(7), 832-848. https://doi.org/10.1080/08870446.2014.891737

Wyman, M. F., Gum, A., \& Arean, P. A. (2011). Psychotherapy with older adults. In M. E. Agronin \& G. J. Maletta (Eds.), Principles and practice of geriatric psychiatry (pp. 177-203). Philadelphia: Lippincott Williams \& Wilkins.

Wyman, M. F., Shiovitz-Ezra, S., \& Bengel, J. (2018). Ageism in the health care system: Providers, patients, and systems. In L. Ayalon \& C. Tesch-Römer (Eds.), Contemporary perspectives on ageism: Vol. 19. International perspectives on aging (pp. 193-213). Berlin: Springer.

Open Access This chapter is licensed under the terms of the Creative Commons Attribution 4.0 International License (http://creativecommons.org/licenses/by/4.0/), which permits use, sharing, adaptation, distribution and reproduction in any medium or format, as long as you give appropriate credit to the original author(s) and the source, provide a link to the Creative Commons license and indicate if changes were made.

The images or other third party material in this chapter are included in the chapter's Creative Commons license, unless indicated otherwise in a credit line to the material. If material is not included in the chapter's Creative Commons license and your intended use is not permitted by statutory regulation or exceeds the permitted use, you will need to obtain permission directly from the copyright holder.

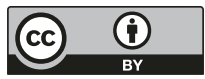

